\title{
Schistosoma mansoni population structure and persistence after praziquantel treatment in two villages of Bahia, Brazil
}

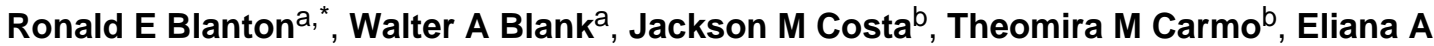 \\ Reis $^{b}$, Luciano K Silva ${ }^{b}$, Lúcio M Barbosa ${ }^{b}$, Matthew R Test ${ }^{a}$, and Mitermayer G Reis ${ }^{b}$ \\ ${ }^{a}$ Case Western Reserve University, Centre for Global Health and Diseases, Wolstein Research \\ Building, 2301 Cornell Road, Cleveland, OH 44106, USA.

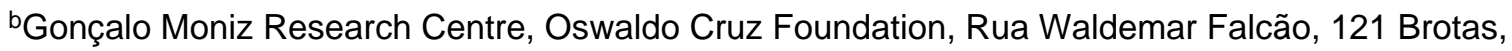 \\ Salvador, Bahia, 40296-710, Brazil.
}

\begin{abstract}
Praziquantel has been used to treat schistosome infections since 1979 and currently is the only chemotherapeutic agent in production for this purpose, raising concerns about the potential for the emergence of drug resistance. In practice, 10-20\% of infected patients will continue to excrete eggs after treatment. It is not understood to what degree this represents selection of a resistant population or incomplete elimination due to the presence of immature worms at the time of treatment. We used a population genetics approach to test whether or not persistent Schistosoma mansoni parasites were drawn from the same population as susceptible parasites. In this study, stool samples were collected from $96 \%$ of individuals in two small Brazilian communities (populations 482 and 367) and examined for S. mansoni eggs. The combined prevalence of $S$. mansoni infections in the villages was $41 \%$. Total egg DNA was extracted from each sample and was genotyped at 15 microsatellite markers. Day-to-day variation of the infrapopulation from an individual human host was low (median differentiation using Jost's $D=0.010$ ), so that a single stool was representative of the genotypes present in stool eggs, at least in the short term. Average pairwise analysis of $D$ among all pre-treatment infrapopulations suggested moderate differentiation (mean $D=0.082$ and 0.122 for the two villages), whereas the pre-treatment component population differentiation between the two communities was 0.047 . The differentiation of the component population remaining after treatment from the fully susceptible component population was low (mean $D=0.007$ and 0.020 for the two villages), suggesting that the persistent parasites were not selected by praziquantel treatment. We will continue to follow these communities for evidence of selection or changes in population structure.
\end{abstract}

\section{Keywords}

Praziquantel; Resistance; Microsatellite; Population genetics; Sampling; Genetic differentiation; Selection

\footnotetext{
"Corresponding author. Address: Wolstein Research Building, 2103 Cornell Rd., Cleveland, OH 44106, USA. Tel.: +1 216368 4814; fax: +1 216368 4825. reb6@ case.edu (R.E. Blanton).

Publisher's Disclaimer: This is a PDF file of an unedited manuscript that has been accepted for publication. As a service to our customers we are providing this early version of the manuscript. The manuscript will undergo copyediting, typesetting, and review of the resulting proof before it is published in its final citable form. Please note that during the production process errors may be discovered which could affect the content, and all legal disclaimers that apply to the journal pertain.
} 


\section{Introduction}

Schistosomiasis is a global health problem. It is an important cause of morbidity wherever it occurs (King et al., 2005). In Brazil, however, it is second only to Chagas disease as a cause of death from parasitic infections and leads important viral and bacterial diseases such as dengue, yellow fever and leptospirosis (Ministry of Health Brazil, DataSUS: Health Information - Vital Statistics: General Mortality, http://tabnet.datasus.gov.br/cgi/deftohtm.exe?sim/cnv/obtuf.def, accession date 12-4-2010). Significant progress has been made in controlling the disease by means of the repeated mass administration of drugs, first oxamniquine and now praziquantel (PZQ). Treatment results in an immediate reduction in the prevalence and intensity of infection but because immunity to infection is weak, reinfection often brings the prevalence back to pre-treatment levels within 2 years (McManus and Loukas, 2008). Currently only PZQ is in use against all species of schistosomes, generating concern about the emergence of drug resistance. In the laboratory, resistance to PZQ can be induced relatively easily using six to seven passages with $\sim 400$ worms in each passage (Fallon and Doenhoff, 1994). Several studies have also indicated that resistance to PZQ can develop in practice (Danso-Appiah and De Vlas, 2002; Melman et al., 2009), although other studies suggest that this occurs quite slowly if at all or that PZQ resistance is associated with reduced parasite fitness (King et al., 2000), also seen for drug resistance in malaria (Babiker et al., 2009). A consistent finding following treatment of populations with PZQ is that $10-20 \%$ of individuals will continue to excrete eggs, usually at a reduced intensity (Wegner, 1984; Cioli and Pica-Mattoccia, 2003). Because immature worms are relatively insensitive to PZQ, the persistence of worms after treatment has commonly been attributed to immature schistosomes from recent infections which subsequently mature (Cioli and Pica-Mattoccia, 2003). It is also possible, however, that these persistent parasites or a portion of them represent a population of adult worms resistant to the drug.

The biology of schistosomes leads to an irregular distribution of genotypes that does not conform to many standard population models and affects how they should be sampled. In the cycle of human schistosome infection, paired male and female worms residing in the intestinal or urinary vasculature produce progeny (eggs) that are excreted. Hatched miracidia undergo asexual reproduction in the snail intermediate host followed by shedding of cercariae and subsequent infection of humans. The population of schistosomes within an individual host, the "infrapopulation" (Bush et al., 1997), can represent infections acquired from multiple sites over years and possibly decades. New individuals join the infrapopulation only by infection (in-migration) and all progeny are exported. Infrapopulations, therefore, need not conform to Hardy-Weinberg expectations. Within a specified geographical area at a given time, the aggregate of infrapopulations in humansthe "component population"-is the pool from which future rounds of infection in that location are drawn (Fig. 1). As a consequence of this uneven distribution, the infrapopulations of a small number or biased sample of individuals may poorly represent the component population.

In addition to the parasite's distribution, population genetic studies on schistosomes present several other difficulties with respect to sampling: worm populations are generally inaccessible in the human host and the cost and effort involved in genotyping individual eggs or miracidia is prohibitive when analyzing many eggs from many infrapopulations. Our approach to these problems is to use allele frequencies obtained from the aggregate of excreted eggs. Data from the individual infrapopulations can then be combined to obtain a portrait of the component population. We and others have previously demonstrated that allele frequencies measured from aggregates of offspring from Schistosoma mansoni (Silva et al., 2006; Blank et al., 2009; Hanelt et al., 2009) and other parasites (Redman et al., 2008) 
reflect the aggregate of allele frequencies obtained by discrete genotyping. Mean error rates for allele frequency estimates of pooled samples range from 2-11\% in these studies. Furthermore, we have shown in laboratory infections of mice that the allele frequencies obtained from eggs also reflect the allele frequencies of the infecting worms (Blank et al., 2011). Genetic differentiation indices using these allele frequencies also follow the known population dynamics of S. mansoni laboratory strains (Blank et al., 2010). By combining a large number of infrapopulations stratified by geographic origin or response to PZQ treatment, this sampling approach allows for population analyses at multiple scales and over time, while avoiding errors due to under sampling.

As part of a comprehensive S. mansoni epidemiological survey and treatment program covering nearly all residents of two communities in the Brazilian state of Bahia, we analyzed the microsatellite allele frequencies of aggregated schistosome eggs recovered from the stool of each infected host. This study investigates the consistency of S. mansoni allele frequencies excreted over multiple days and examines the changes in allele frequencies observed in those schistosome infections that persist after PZQ treatment. Finally, we explore the potential for this approach to detect the hypothetical resistance to PZQ in persistent S. mansoni populations.

\section{Materials and methods}

\subsection{Population}

The villages of Jenipapo and Volta do Rio in the East Central region of the state of Bahia, Brazil were selected for their reported high prevalence of $S$. mansoni infection and their well-defined geographic limits. The two communities are $12 \mathrm{~km}$ apart and are connected by the Jiquiriçá River and a two-lane highway. The region consists of steep river valleys with rolling hills and is primarily devoted to raising cattle and other livestock. A census was performed for all households at the start of the study and all residents $>1$ year of age were invited to participate. Participants or guardians responded to a brief questionnaire on demographic characteristics and prior treatment for parasites. They were also asked to provide whole stool samples for examination on three different days within the same week. Both communities are administratively governed from the district's largest city, Ubaíra. Jenipapo (population 82 in 2009) has a Federal Family Health Program post with a permanent staff of a nurse, dentist and part-time physician. A laboratory adjacent to the post was used for all stool examinations. The primary and secondary schools for the nearby small communities, including Volta do Rio, are located in Jenipapo. Volta do Rio (population 367 in 2009) has a simple health post staffed by a group of nurses. The Committee on Ethics in Research of the Oswaldo Cruz Foundation of Salvador, Bahia, the Brazilian National Committee on Ethics in Research and the Institutional Review Board for Human Investigation of University Hospitals Case Medical Centre, Cleveland, Ohio approved the study design.

\subsection{Stool survey and egg isolation}

Morning stools collected from participants were weighed, single slides were prepared by the Kato-Katz method (Katz et al., 1972), and the slides were read on the same day to determine the number of eggs per gram in each sample. The following day, whole stools that were positive for $S$. mansoni were processed to obtain eggs. Stools were homogenized in a blender with $200 \mathrm{ml}$ of $2 \%$ saline followed by selective sieving (Dresden and Payne, 1981) through $300 \mu \mathrm{m}$ and $55 \mu \mathrm{m}$ mesh nylon filter bags (FSI, Michigan City, Indiana, USA) and sedimentation in $2 \%$ saline. The bottom $5 \mathrm{ml}$ of sediment was collected and then kept frozen at $-20^{\circ} \mathrm{C}$ until used for DNA isolation. In accordance with Brazilian Ministry of Health guidelines (Ministry of Health Brazil, 2005), participants with one or more egg-positive 
stools were given PZQ $(50 \mathrm{mg} / \mathrm{kg}$ ) once, and three follow-up stool examinations were performed on these individuals 4-6 weeks later, together with egg isolations as before.

\subsection{DNA isolation}

The $5 \mathrm{ml}$ frozen stool sediment was mixed with $5 \mathrm{ml} 2 \mathrm{X}$ extraction buffer $(50 \mathrm{mM} \mathrm{NaCl}$, $100 \mathrm{mM}$ Tris- $\mathrm{HCl}, \mathrm{pH}$ 7.5, $10 \mathrm{mM}$ EDTA, $1.0 \%$ SDS) and $10 \mathrm{ml} \mathrm{H}_{2} \mathrm{O}$-saturated and Trisbuffered phenol, $\mathrm{pH}$ 7.5. This was mixed by rocking for $5 \mathrm{~min}$, then $10 \mathrm{ml}$ of chloroform/ isoamyl alcohol (23:1) was added and rocking continued for another 5 min. Following centrifugation, the aqueous portion was removed and extracted twice with $10 \mathrm{ml}$ chloroform/ isoamyl alcohol. The DNA was then ethanol precipitated and suspended in $10 \mathrm{mM}$ Tris, $\mathrm{pH}$ 7.5, 1 mM EDTA. Further cleanup using hexadecyltrimethyl ammonium bromide (CTAB) was performed to remove PCR inhibitors (Ausubel et al., 1987).

\subsection{Quantitative PCR (qPCR) and PCR amplification}

Since the faecal sediment was not exclusively composed of $S$. mansoni eggs, the amount of specific $S$. mansoni DNA was quantified by qPCR by the method of Gomes et al. (2006) which amplifies a $S$. mansoni ssrRNA fragment. Real-time PCR was performed with the AB 7300 Real-Time PCR system (Applied Biosystems) using SYBR-Green qPCR master mix (Roche). Serial dilutions of adult worm DNA were used to generate a standard curve based on concentrations determined with a NanoDrop 1000 spectrophotometer (Thermo Scientific).

\subsection{Microsatellite genotyping}

Fifteen microsatellite markers (Table 1) were used in this study. Eleven were previously published (Durand et al., 2000; Curtis et al., 2001; Rodrigues et al., 2002; Silva et al., 2006; Blank et al., 2010), and primers for markers not previously described are as follows: SM13410 (F: TGACTTTGAATCCAACAGAGACC, R: GTTTGCTCAGAGACCTGAACCTAC), 29E6A (F: ACATCCAGCTGACGAGTCC, R: ACTGCCCTATTCCTAACTGGC), SM13-478 (F: CAGGAATTTGTATTGTTCTGCTGTC, R: ACAGTGGCTAACTGACTACG), and 15J15A (F: TGTGGTTAATCGCTGCTACC, R: GTTTCATGCCAACTGCGTCTC). Primer design and PCR genotyping were performed as described previously (Blank et al., 2010). Briefly, duplicate PCR reactions using $2 \mu 1$ of extracted DNA were performed for each of the 15 marker loci, totalling 30 reactions per sample. PCR products from each sample were combined into groups of three or four markers and processed on an Applied Biosystems 3730xl DNA Analyzer. PeakScanner software (Applied Biosystems) was used to determine peak heights from which allele frequencies were calculated. Successful PCR reactions were defined as those in which measurable peaks in the size range expected for a given marker were observed. Subsequent population analyses were limited to those samples that had a minimum of 25 successful PCRs out of the 30 performed on each sample.

\subsection{Data analysis}

Categorical comparisons of survey data between villages (sex ratios, birthplace, treatment history) were made using Yates' corrected chi-square analysis. Age, years of residence and $S$. mansoni infection intensity were analyzed by Student's $t$-test. For all statistical tests, a $P$ value of $<0.05$ was deemed significant. Unless otherwise indicated, averages are reported as means \pm S.D. when values approximated a normal distribution and as medians with the first and third quartile values for skewed distributions. Statistical analyses were performed using $\mathrm{R}$ version 2.12.1 (R: A language and environment for statistical computing. R Foundation for Statistical Computing, Vienna, Austria. URL: http://www.R-project.org). 
Allele counts for each sample were calculated by multiplying the allele frequencies at a microsatellite locus by the total egg counts. Infrapopulations were stratified according to the host's village of residence and whether or not eggs were observed in follow-up samples after treatment with PZQ (persistent and susceptible, respectively). Persistent infrapopulations were also stratified by whether they were collected pre- or post-treatment. Component population allele frequencies were calculated as the sum of the allele counts from individual infrapopulations. Genetic differentiation between populations was expressed as the index $D$ (Jost, 2008) calculated using the program SPADE (Chao and Shen, 2010. SPADE: Species Prediction And Diversity Estimation. URL: http://chao.stat.nthu.edu.tw). $D$ is a true differentiation index and does not rely on assumptions of Hardy-Weinberg equilibrium that may not hold for infrapopulations. The $D$ value reported for any given comparison in this study was the mean $D$ across all the markers used. Following the convention used for interpreting $F_{S T}$ values (Hartl and Clark, 2007), $D$ values up to 0.05 indicate little differentiation; from 0.05 to 0.15 , moderate differentiation; and above 0.15 , great differentiation.

\section{Results}

\subsection{Infection prevalence and intensity}

The populations of the two communities were comparable in terms of sex ratios, age, place of birth, portion of life spent in the community, previous treatment and infection intensity (Table 2). Approximately $30 \%$ of the total population reported prior treatment for schistosomiasis, and $62 \%$ of these could identify the medication used. Only $24 \%$ of those who reported prior treatment said they had been treated with PZQ. The proportion that reported taking PZQ in Jenipapo was twice that of Volta do Rio. These responses appear to be consistent with the history of PZQ use in the region. One individual, however, reported treatment with PZQ in 1994, prior to this drug's common use by public health authorities, and another reported treatment with pyrantel pamoate, which is not used for schistosomiasis. Otherwise the reporting was credible.

Of the 482 residents registered in Jenipapo, 458 (95\%) participated in the stool survey, while 357 of the 367 (97\%) residents of Volta do Rio participated. Two of the 34 residents not examined were lost from the study due to migration; the remainder refused to provide a stool sample. At least one stool sample was provided by $96 \%$ of the total population of both communities, $94 \%$ provided a second sample and $93 \%$ provided a third. Stool examination by the Kato-Katz method showed that $41 \%$ of the overall population was positive for $S$. mansoni on at least one stool exam. The prevalence of schistosomiasis was significantly higher in Jenipapo (43.6 versus $33.8 \%, P=0.005$ ), although the mean intensity of infection was not significantly different between the communities. In Jenipapo, $92.3 \%$ of those infected became egg negative following treatment and $84.7 \%$ in Volta do Rio.

\subsection{Sample selection and genotyping success}

Samples chosen for genotyping in this study were from two overlapping groups. The first group, selected to evaluate the day-to-day variation in allele frequencies of excreted egg populations, consisted of samples from individuals with three egg-positive stools collected prior to PZQ treatment (348 samples from 116 individuals). The second group was selected to determine the effect of PZQ treatment on persistent infections and therefore consisted of pre- and post-treatment samples from individuals whose post-treatment stool was found to contain eggs (120 samples from 33 individuals). Thirteen individuals with persistent infections were also among the individuals with three positive pre-treatment samples. In total, 429 samples from 136 individuals were subjected to duplicate PCRs at 15 microsatellite markers. 
Three hundred and fifty-eight samples (83\% of the total) were genotyped successfully as defined by a minimum of 25 of the 30 PCRs producing scorable results. Of these, 269 (75\%) were typed at all 15 markers, $65(18 \%)$ at 14 markers, and the remaining $24(7 \%)$ at 13 markers. Sample genotyping success correlated with the amount of $S$. mansoni DNA present in the sample (Spearman's rank correlation coefficient $=0.58$; Fig. 2). Greater than $90 \%$ of samples that contained at least $25 \mathrm{pg} / \mu \mathrm{L}$ of $S$. mansoni DNA were genotyped successfully.

Of the 33 individuals with persistent infections, 23 had samples of sufficient quality for analysis both before and after PZQ treatment. In an additional three samples, only posttreatment samples were successfully typed. With respect to microsatellite success, 11 of the 15 markers were scorable in over $90 \%$ of reactions, 14 markers in over $80 \%$ of reactions. In those samples with at least 25 successful reactions, 14 markers had $>90 \%$ success rate and the success of the poorest marker (SMMS13) was 74\% (Table 3).

\subsection{Infrapopulation differentiation}

To determine the day-to-day consistency of genotype excretion, we determined $D$ between stool samples collected from the same individual on different days. A total of 282 samples from 103 individuals were examined, giving 255 within-individual, day-to-day pairwise comparisons. The median day-to-day differentiation within an individual host was 0.010 (first quartile 0.004, third quartile 0.019). To establish a baseline for consistency, the median $D$ between duplicate assays for the same sample (282 comparisons) was 0.007 (first quartile 0.004 , third quartile 0.015 ), which may be considered near the limit of detection for differentiation between infrapopulations using this approach.

Pairwise $D$ values between individual infrapopulations in Jenipapo and Volta do Rio were determined based on mean infrapopulation allele frequencies and egg counts. The pretreatment infrapopulations of Volta do Rio were significantly more differentiated from each other than were those of Jenipapo (Table 4), although similar differentiation was observed among post-treatment infrapopulations in both villages. Mean pairwise differentiation among all pre- and post-treatment infrapopulations was significantly higher between villages than within either village (with the exception of susceptible infrapopulations from Volta do Rio, $P=0.06$, not shown), indicating a degree of reproductive isolation between the villages.

\subsection{Component population differentiation}

Egg allele frequencies from the pre- and post-treatment infrapopulation groups were combined by village to give allele frequencies of the component populations. Pairwise $D$ analysis of these component populations (Table 5) showed that there likely were some barriers to gene flow between village populations $(D=0.047$ for pre-treatment populations; $D=0.063$ post-treatment).

Prior to treatment, the susceptible component populations from the two villages were little differentiated from their respective persistent populations ( $D \leq 0.010$; Table 5). When stratified by village, differentiation was likewise low between PZQ susceptible and posttreatment persistent component populations in Jenipapo $(D=0.007)$ and slightly higher for Volta do Rio $(D=0.020)$. The pre- and post-treatment persistent component populations showed little differentiation within each village $(D=0.006$, Jenipapo; $D=0.007$, Volta do Rio).

A reduction in intensity of infection is expected after PZQ treatment, even if the individual is not ultimately egg-free. The mean intensity reduction in persistent infections was $63 \%$ in Jenipapo and 83\% in Volta do Rio. For some of the persistent infections, however, there was no reduction or there was even an increase in the intensity of infection. Some of these likely represented individuals who did not take PZQ. To assess whether there were population 
differences in those with or without reduction in egg burden, we grouped the persistent infections by whether or not they exhibited a reduction in infection intensity and compared the infrapopulation pre- versus post-treatment $D$ values for the two groups (Fig. 3). The distribution of $D$ s between the reduced and non-reduced populations was not found to differ significantly (medians 0.024 and 0.029 , respectively; Wilcoxon rank-sum test $P=0.841$ ). Analyzed from several perspectives, the persistent populations were not differentiated from the susceptible populations.

\section{Discussion}

Much of the focus on selection in population genetics is on events that occur over an evolutionary time frame, but when selection pressure is exerted by use of antimicrobial agents, the effect of a selection event can be observed after a very short period of time. In prokaryotes, antimicrobial selection often results in overgrowth of a clone (Soares et al., 1993; Davis et al., 1999; Manges et al., 2001; Martin et al., 2002) and is thus easy to identify using common molecular tools. Sexual reproduction never produces clones, but rather families in which the genotypes among the members are more closely correlated than unrelated or more distantly related members of a population. Since useful mutations often develop on one or a few genotypes, in the short-term, the average degree of relationship among resistant organisms is likely to be higher than the average degree of relationship among susceptible organisms. In the absence of isolation and over many generations, polymorphisms associated with resistance may be distributed to other genotypes, and familial relationships may be less apparent. At the moment of a selective sweep and prior to reproduction, however, the distribution of surviving genotypes is likely not to be random. They are likely to represent an extended family of individuals more closely related to each other at many loci than the susceptible population.

Measurement of accuracy and error are complex for the population genetics of schistosomes since there are two scales to be considered. At one scale there is the error of individual genotyping compared with genotyping pools of individuals. This error ranges from $2-11 \%$ based on our own studies (Silva et al., 2006; Blank et al., 2009; Hanelt et al., 2009) and those of others (Redman et al., 2008). However, when we compared the $\mathrm{F}_{\mathrm{ST}}$ based on genotyping individuals or pools, we found that the differences had little effect on the $\mathrm{F}_{\mathrm{ST}}$ and is unlikely to significantly affect other measures of differentiation. The second source of error exemplified in Fig. 1 results from the compartmentalization of genotypes in infrapopulations. The almost complete sampling of all infrapopulations here avoids error due to undersampling, which we show could potentially be substantial given the degree of differentiation between infrapopulations.

Given a model where resistance arises in a limited number of organisms, we would predict that if schistosomes persist following treatment with PZQ due to a shared selective advantage, the persistent infrapopulations would be more related to each other than to the susceptible populations. What we observed was that the schistosome populations that persist are essentially randomly drawn from the overall population and not a selected population. This is consistent with the recent introduction of PZQ for widespread treatment of $S$. mansoni infections in Brazil and its limited use to date in these communities. The lack of differentiation from the overall population and lack of similarity within the persistent populations supports the common presumption that persistent populations represent recent transmission (Cioli, 2000; Gryseels et al., 2001; Cioli and Pica-Mattoccia, 2003). Since for the first 4 weeks following infection $S$. mansoni is relatively insensitive to PZQ, any recently acquired infections will not be affected by the administration of these drugs. These will appear as persistent infections, although the parasites will be drawn from the overall 
susceptible population. It is also possible worms may be in a location protected from the drug or that host factors governing drug metabolism randomly affect worm survival.

There are other models for the development of resistance under which these assumptions would not hold. Resistance to an antimicrobial agent may develop on multiple genotypes or by means of mobile elements in which case the genomes of resistant organisms will not show an overall correlation. Another caveat for any interpretation is that the marker panel used is not large and does not provide dense coverage of the genome. We are, however, able to show infrapopulation variation within these small communities, genetic drift within a laboratory strain (Blank et al., 2010), and demonstrate variation between subsamples of an $S$. mansoni laboratory population using a marker panel of similar size (Blank et al., 2011). Finally, there is a precedent for selection producing detectable differentiation across neutral unlinked markers (Merilä and Crnokrak; Freeland et al., 2010; Johansson et al., 2010). Since in this study we see little pre- and post-treatment differentiation for the component populations of the communities studied, this is suggestive evidence of a lack of selection.

One other study has examined $S$. mansoni population structure in the context of a treatment program. Norton et al. (2010) conducted a study in Tanzania analyzing individual miracidia from 80 children prior to PZQ treatment and from 47 children at follow-up 1 year posttreatment. The individuals included in the pre- and post-treatment groups did not completely overlap. The study found a marked reduction in parasite allelic richness, which was attributed primarily to a population bottleneck resulting from mass community-wide administration of PZQ. Pre- and post-treatment populations a year later were not similar, however this study primarily examined re-infection rather than persistent infections. The potential for drug resistance was considered as an explanation for some observations, but thought unlikely given the modest prior exposure of the population to PZQ in these communities. It is difficult to make comparisons with the present study since the location and sampling strategies were so different and Norton et al, (2010) did not analyze infrapopulation differentiation. Two-year follow-up studies in Jenipapo and Volta do Rio are planned to determine the longer-term impact on the parasite populations.

In addition to investigating selection, the approach taken in this study has allowed us to sample whole communities widely and begin to understand important aspects of baseline genetic diversity within and among subpopulations. We find that at least over the period of 1 week, the excretion of parasite genotypes is consistent day-to-day. In theory, a single stool would suffice to represent the individual host's infrapopulation. We also found that in these communities, there is a moderate degree of differentiation of the infrapopulations among hosts. Parasites are probably acquired a few at a time by each host at different locations and under different circumstances. When the component population is very heterogeneous, any individual host will carry a very incomplete sample of the component population. For this reason the component population differentiation between villages is lower than the infrapopulation differentiation within each of the communities. This is consistent with each infrapopulation representing a limited draw from the overall pool. Sampling of infrapopulations needs to be extensive to capture the variability in the component population and under sampling is likely to overestimate differentiation at this level. We will continue to monitor the response to therapy and the population structure in these communities following repeated rounds of PZQ treatment using the techniques we have developed.

\section{Highlights}

$>\quad$ Schistosoma mansoni egg genotypes stable for at least 1 week.

$>\quad$ Moderate infrapopulation differentiation within villages. 


\section{> Moderate geographic differentiation between villages. \\ $>\quad$ Little differentiation between susceptible and persistent populations after praziquantel. \\ $>\quad$ Evidence for lack of resistance in populations that persist after praziquantel.}

\section{Acknowledgments}

This work was supported by NIH R01 R01 AI069195 and the Fulbright Brasil Scholar Program. The authors would like to thank Jeffrey C. Long, University of New Mexico (USA), Department of Anthropology for useful comments and suggestions for the manuscript.

\section{References}

Ausubel, FM.; Brent, R.; Kingston, RE.; Moore, DD.; Seidman, JG.; Smith, JA.; Struhl, K. Current Protocols in Molecular Biology. New York: Green Publishing Associates and Wiley Inter-science; 1987.

Babiker HA, Hastings IM, Swedberg G. Impaired fitness of drug-resistant malaria parasites: evidence and implication on drug-deployment policies. Expert Rev. Anti. Infect. Ther. 2009; 7:581-593. [PubMed: 19485798]

Blank W, Liu S, Prasad J, Blanton R. Mouse strain type is not selective for Schistosoma mansoni. J. Parasitol. 2011; 97:518-521. [PubMed: 21506771]

Blank WA, Reis EA, Thiong'o FW, Braghiroli JF, Santos JM, Melo PR, Guimaraes IC, Silva LK, Carmo TM, Reis MG, Blanton RE. Analysis of Schistosoma mansoni population structure using total fecal egg sampling. J. Parasitol. 2009; 95:881-889. [PubMed: 20049994]

Blank WA, Test MR, Liu SF, Lewis FA, Blanton RE. Long-term genetic stability and population dynamics of laboratory strains of Schistosoma mansoni. J. Parasitol. 2010; 96:900-907. [PubMed: 20950096]

Bush AO, Lafferty KD, Lotz JM, Shostak AW. Parasitology meets ecology on its own terms: Margolis et al. revisited. J. Parasitol. 1997; 83:575-583. [PubMed: 9267395]

Cioli D. Praziquantel: is there real resistance and are there alternatives? Curr. Opin. Infect. Dis. 2000; 13:659. [PubMed: 11964838]

Cioli D, Pica-Mattoccia L. Praziquantel. Parasitol. Res. 2003; 90 Supp 1:S3-S9. [PubMed: 12811543]

Curtis J, Fraga LA, de Souza CP, Correa-Oliveira R, Minchella DJ. Widespread heteroplasmy in schistosomes makes an mtVNTR marker "nearsighted". J. Hered. 2001; 92:248-253. [PubMed: 11447240]

Danso-Appiah A, De Vlas SJ. Interpreting low praziquantel cure rates of Schistosoma mansoni infections in Senegal. Trends Parasitol. 2002; 18:125-129. [PubMed: 11854090]

Davis MA, Hancock DD, Besser TE, Rice DH, Gay JM, Gay C, Gearhart L, DiGiacomo R. Changes in antimicrobial resistance among Salmonella enterica Serovar typhimurium isolates from humans and cattle in the Northwestern United States, 1982-1997. Emerg. Infect. Dis. 1999; 5:802-806. [PubMed: 10603215]

Dresden MH, Payne DC. A sieving method for the collection of schistosome eggs from mouse intestines. J Parasitol. 1981; 67:450-452. [PubMed: 7196444]

Durand P, Sire C, Theron A. Isolation of microsatellite markers in the digenetic trematode Schistosoma mansoni from Guadeloupe island. Mol. Ecol. 2000; 9:997-998. [PubMed: 10886664]

Fallon PG, Doenhoff MJ. Drug-resistant schistosomiasis: resistance to praziquantel and oxamniquine induced in Schistosoma mansoni in mice is drug specific. Am. J. Trop. Med. Hyg. 1994; 51:83-88. [PubMed: 8059919]

Freeland JR, Biss P, Conrad KF, Silvertown J. Selection pressures have caused genome-wide population differentiation of Anthoxanthum odoratum despite the potential for high gene flow. J. Evol. Biol. 2010; 23:776-782. [PubMed: 20163507] 
Gryseels B, Mbaye A, De Vlas SJ, Stelma FF, Guisse F, Van Lieshout L, Faye D, Diop M, Ly A, Tchuem Tchuenté LA. Are poor responses to praziquantel for the treatment of Schistosoma mansoni infections in Senegal due to resistance? An overview of the evidence. Trop. Med. Int. Health. 2001; 6:864-873. [PubMed: 11703840]

Hanelt B, Steinauer ML, Mwangi IN, Maina GM, Agola LE, Mkoji GM, Loker ES. A new approach to characterize populations of Schistosoma mansoni from humans: development and assessment of microsatellite analysis of pooled miracidia. Trop. Med. Int. Health. 2009; 14:322-331. [PubMed: 19187519]

Hartl, DL.; Clark, AG. Principles of Population Genetics. Sunderland, Massachusetts: Sinauer Associates; 2007.

Johansson AM, Pettersson ME, Siegel PB, Carlborg O. Genome-wide effects of long-term divergent selection. PLoS Genet. 2010; 6:e1001188. [PubMed: 21079680]

Jost L. $G_{\mathrm{ST}}$ and its relatives do not measure differentiation. Mol. Ecol. 2008; 17:4015-4026. [PubMed: 19238703]

Katz N, Chaves A, Pellegrino J. A simple device for quantitative stool thick-smear technique in schistosomiasis mansoni. Rev. Inst. Med. Trop. São Paulo. 1972; 14:397-400.

King CH, Muchiri EM, Ouma JH. Evidence against rapid emergence of praziquantel resistance in Schistosoma haematobium, Kenya. Emerg. Infect. Dis. 2000; 6:585-594. [PubMed: 11076716]

King CH, Dickman K, Tisch DJ. Reassessment of the cost of chronic helmintic infection: a metaanalysis of disability-related outcomes in endemic schistosomiasis. Lancet. 2005; 365:1561-1569. [PubMed: 15866310]

Manges AR, Johnson JR, Foxman B, O'Bryan TT, Fullerton KE, Riley LW. Widespread distribution of urinary tract infections caused by a multidrug-resistant Escherichia coli clonal group. N. Engl. J. Med. 2001; 345:1007-1013. [PubMed: 11586952]

Martin JM, Green M, Barbadora KA, Wald ER. Erythromycin-resistant group A streptococci in schoolchildren in Pittsburgh. N. Engl. J. Med. 2002; 346:1200-1206. [PubMed: 11961148]

McManus DP, Loukas A. Current status of vaccines for schistosomiasis. Clin. Microbiol. Rev. 2008; 21:225-242. [PubMed: 18202444]

Melman SD, Steinauer ML, Cunningham C, Kubatko LS, Mwangi IN, Wynn NB, Mutuku MW, Karanja DM, Colley DG, Black CL, Secor WE, Mkoji GM, Loker ES. Reduced susceptibility to praziquantel among naturally occurring Kenyan isolates of Schistosoma mansoni. PLoS Negl. Trop. Dis. 2009; 3:e504. [PubMed: 19688043]

Merilä J, Crnokrak P. Comparison of genetic differentiation at marker loci and quantitative traits. J. Evol. Biol. 2001; 14:892-903.

Ministry of Health, Brazil. Brazil, Brasilia: Ministry of Health; 2005. Guide to Epidemiological Surveillance [Guia de Vigilância Epidemiológica].

Norton AJ, Gower CM, Lamberton PHL, Webster BL, Lwambo NJS, Blair L, Fenwick A, Webster JP. Genetic consequences of mass human chemotherapy for Schistosoma mansoni: population structure pre-and post-praziquantel treatment in Tanzania. Am. J. Trop. Med. Hyg. 2010; 83:951. [PubMed: 20889898]

Redman E, Packard E, Grillo V, Smith J, Jackson F, Gilleard JS. Microsatellite analysis reveals marked genetic differentiation between Haemonchus contortus laboratory isolates and provides a rapid system of genetic fingerprinting. Int. J. Parasitol. 2008; 38:111-122. [PubMed: 17727857]

Rodrigues NB, Loverde PT, Romanha AJ, Oliveira G. Characterization of new Schistosoma mansoni microsatellite loci in sequences obtained from public DNA databases and microsatellite enriched genomic libraries. Mem. Inst. Oswaldo Cruz. 2002; 97 Suppl 1:71-75. [PubMed: 12426598]

Silva LK, Liu S, Blanton RE. Microsatellite analysis of pooled Schistosoma mansoni DNA: an approach for studies of parasite populations. Parasitology. 2006; 132:331-338. [PubMed: 16255835]

Soares S, Kristinsson KG, Musser JM, Tomasz A. Evidence for the introduction of a multiresistant clone of serotype 6B Streptococcus pneumoniae from Spain to Iceland in the late 1980s. J. Infect. Dis. 1993; 168:158-163. [PubMed: 8515104]

Wegner DH. The profile of the trematodicidal compound praziquantel. Arzneimittelforschung. 1984; 34:1132-1136. [PubMed: 6391500] 


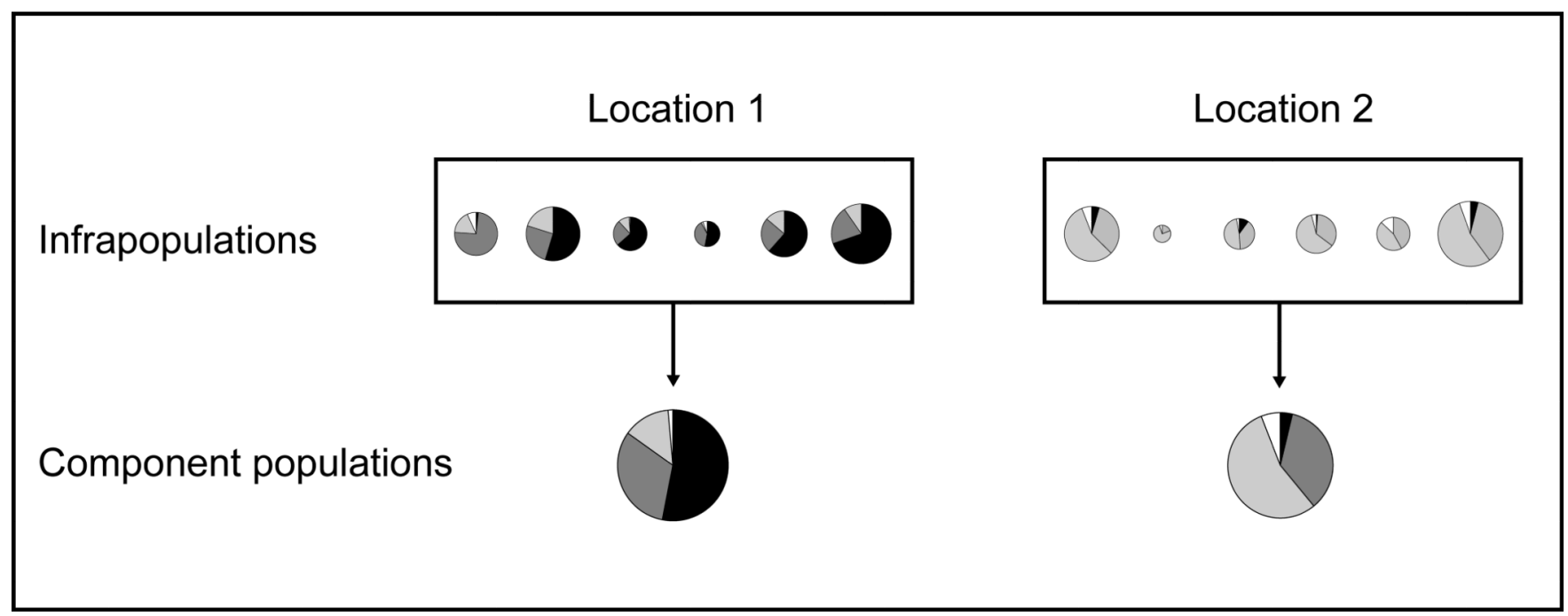

Fig. 1.

Diagrammatic representation of allele frequency distribution between two hypothetical locations. In each location, six infrapopulations of varying sizes are combined to represent the component population. 


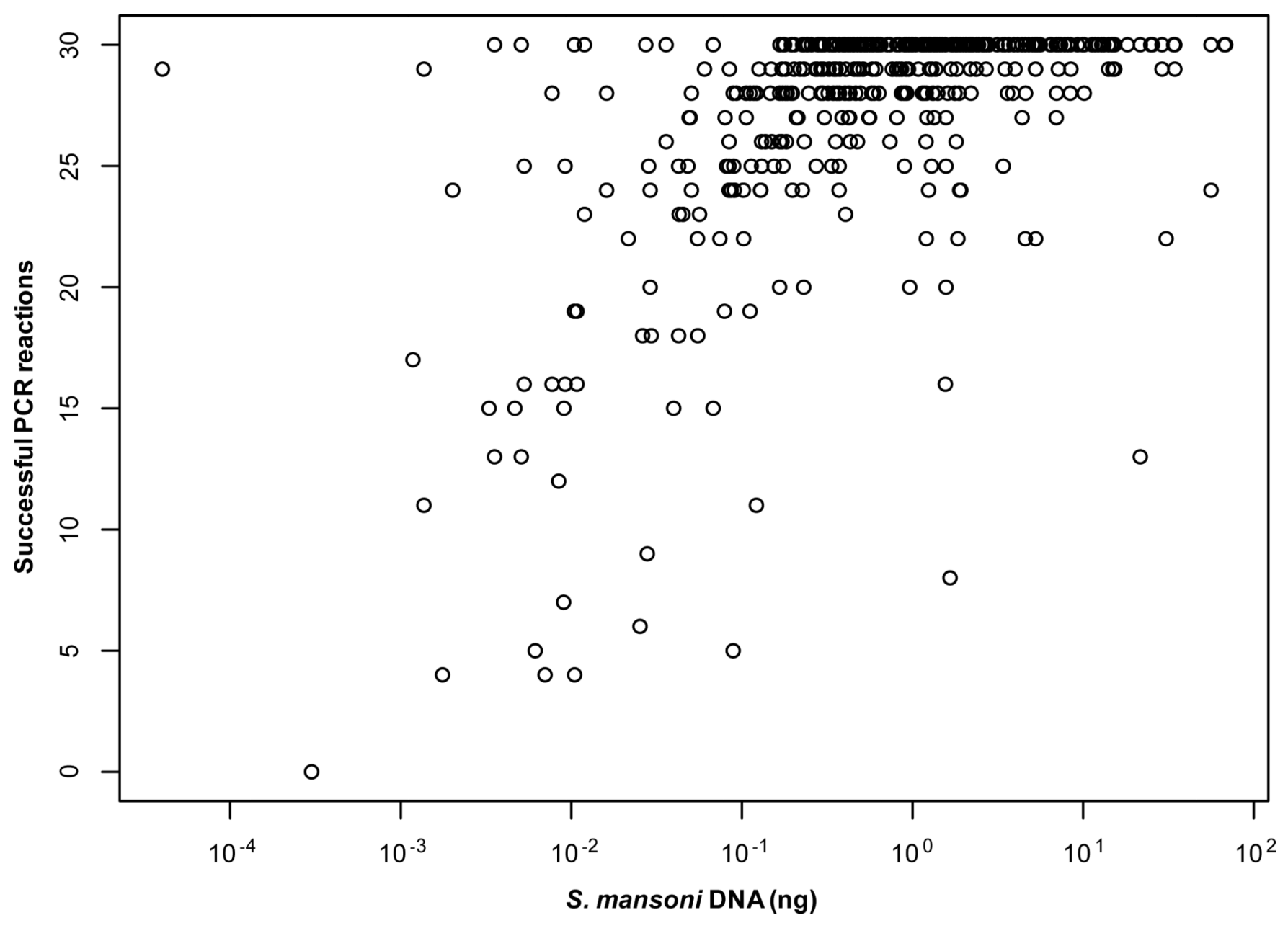

Fig. 2.

PCR success versus quantity of Schistosoma mansoni DNA. DNA quantity was determined by quantitative PCR. Duplicate reactions were performed for 15 markers and the number of amplifications obtained for each sample was plotted. $n=429$ samples. 


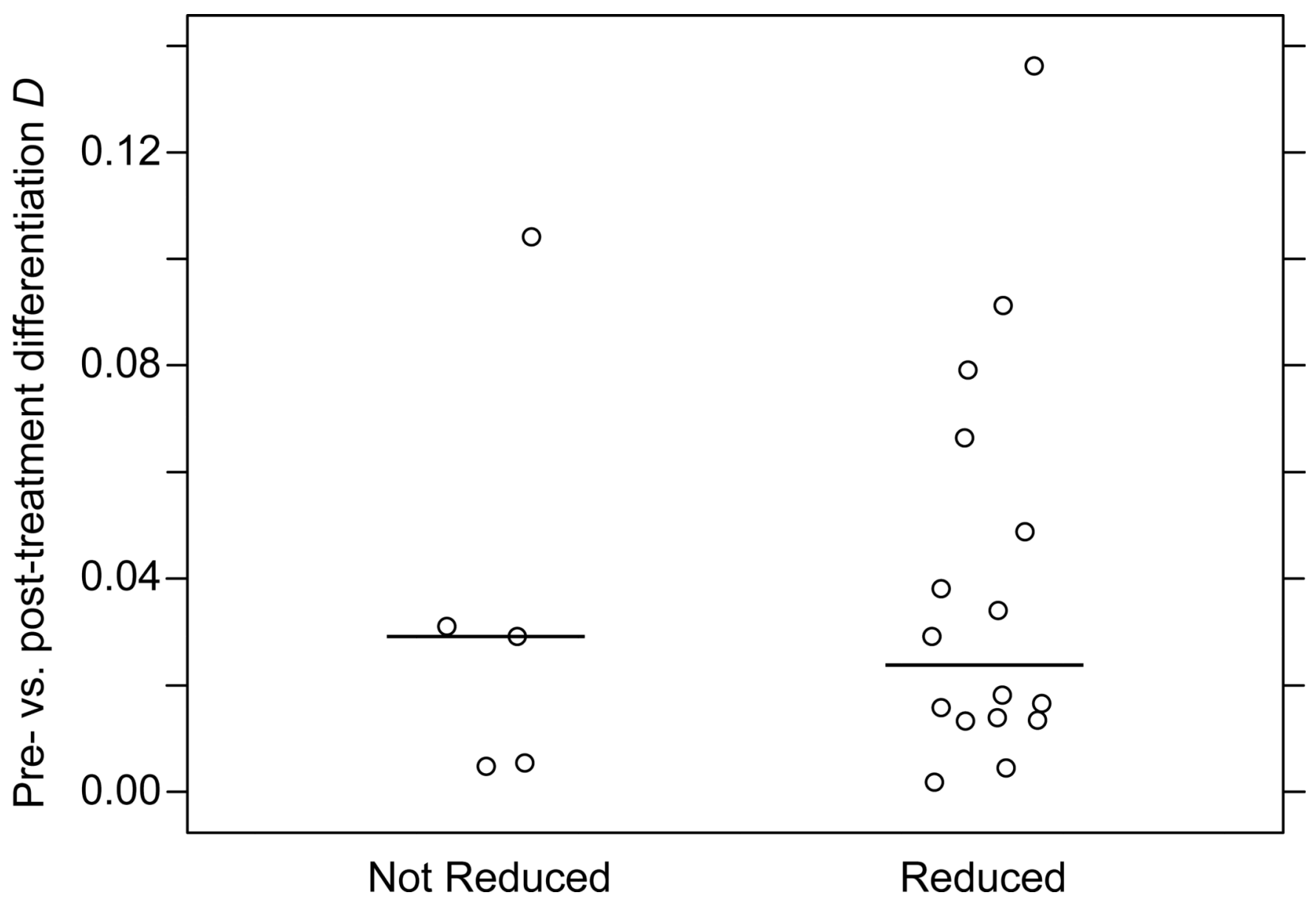

Fig. 3.

Distribution of $D$ values for infrapopulations from the same individual pre- and posttreatment. Infrapopulations for which there was no reduction in egg counts $(n=5)$ and those with a reduction $(n=16)$ were grouped together. The horizontal bar represents median $D$ for each group. 
Table 1

Summary of microsatellite markers used in this study.

\begin{tabular}{|c|c|c|c|c|}
\hline $\begin{array}{c}\text { Genotyping } \\
\text { Group }\end{array}$ & Locus & Reference & $\begin{array}{c}\text { Size } \\
\text { range }\left(n t^{a}\right)\end{array}$ & $\begin{array}{c}\text { Alleles } \\
\text { Observed }\end{array}$ \\
\hline \multirow{3}{*}{ I } & SMMS2 & Silva et al., 2006 & $212-235$ & 4 \\
\hline & SMMS13 & Silva et al., 2006 & $183-192$ & 4 \\
\hline & SMMS16 & Silva et al., 2006 & $211-229$ & 7 \\
\hline \multirow{4}{*}{ II } & SMMS3 & Silva et al., 2006 & $176-209$ & 12 \\
\hline & SMMS17 & Silva et al., 2006 & $286-304$ & 7 \\
\hline & SMMS18 & Silva et al., 2006 & $195-228$ & 12 \\
\hline & SMMS21 & Silva et al., 2006 & $174-186$ & 5 \\
\hline \multirow{4}{*}{ IV } & 13TAGA & Rodrigues et al., 2002 & $103-143$ & 11 \\
\hline & SMDA23 & Curtis et al., 2001 & $193-237$ & 12 \\
\hline & $1 \mathrm{~F} 8 \mathrm{~A}$ & Blank et al., 2010 & $151-172$ & 8 \\
\hline & SM13-410 & This study & $192-207$ & 6 \\
\hline \multirow{4}{*}{ V } & 29E6A & This study & $160-178$ & 7 \\
\hline & SM13-478 & This study & $225-258$ & 12 \\
\hline & $15 \mathrm{~J} 15 \mathrm{~A}$ & This study & $208-232$ & 9 \\
\hline & SMU31768 & Durand et al., 2000 & $190-226$ & 13 \\
\hline
\end{tabular}

$a_{\text {nt, nucleotide }}$ 
Table 2

Demographics, treatment history and Schistosoma mansoni infection status of communities examined in this study.

\begin{tabular}{|c|c|c|c|}
\hline \multirow[t]{2}{*}{ Characteristic } & \multicolumn{2}{|c|}{ Community } & \\
\hline & $\begin{array}{c}\text { Jenipapo } \\
n=482\end{array}$ & $\begin{array}{c}\text { Volta do Rio } \\
\quad n=\mathbf{3 6 7}\end{array}$ & \\
\hline \multicolumn{4}{|l|}{ Sex } \\
\hline Male (\%) & $234(48.5)$ & $166(47.8)$ & \\
\hline Female $(\%)$ & $248(51.5)$ & $201(52.2)$ & \\
\hline \multicolumn{4}{|l|}{ Age (years) } \\
\hline Mean (S.D.) & $30.5(21.6)$ & $32.5(25.3)$ & \\
\hline Min.-Max. & $1-101$ & $1-91$ & \\
\hline \multicolumn{4}{|l|}{ Birthplace } \\
\hline Within district (\%) & $407(84.4)$ & $300(81.7)$ & \\
\hline Other $(\%)$ & $75(15.6)$ & $67(18.3)$ & \\
\hline$\%$ of lifespan in district & 92.8 & 90.2 & \\
\hline \multicolumn{4}{|l|}{ Previous treatment ${ }^{a}$} \\
\hline Treated $(\%)$ & $166(34.4)$ & $121(33.0)$ & \\
\hline Not treated $(\%)$ & $14(2.9)$ & $6(1.6)$ & \\
\hline Do not know (\%) & $302(62.7)$ & $240(66.4)$ & \\
\hline \multicolumn{4}{|l|}{ Medication used ${ }^{a}$} \\
\hline Oxamniquine (\%) & $112\left(70.4^{b}\right)$ & $66(85.7)$ & \multirow{2}{*}{$P=0.02^{c}$} \\
\hline Praziquantel (\%) & 47 (29.6) & $11(14.3)$ & \\
\hline \multicolumn{4}{|l|}{ S. mansoni infection } \\
\hline \multicolumn{4}{|l|}{ Pretreatment } \\
\hline Prevalence $(\%)$ & $210(43.6)$ & $124(33.8)$ & $P<0.01^{c}$ \\
\hline Intensity ${ }^{e}$ (S.D.) & $278(4.1)$ & $435(4.4)$ & $P=0.26^{d}$ \\
\hline \multicolumn{4}{|l|}{ Post-treatment } \\
\hline Prevalence (\%) & $16(7.6)$ & $17(15.3)$ & $P=0.07$ \\
\hline Intensity ${ }^{e}$ (S.D.) & $25(3.9)$ & $71(3.8)$ & $P=0.03$ \\
\hline \multicolumn{4}{|l|}{ Self-reported } \\
\hline \multicolumn{4}{|c|}{ Percentage of those identifying a medication } \\
\hline \multicolumn{4}{|c|}{${ }^{c}$ Yates' corrected chi-square test } \\
\hline
\end{tabular}


Table 3

Genotyping success for samples in this study by microsatellite marker.

\begin{tabular}{|c|c|c|c|c|}
\hline \multirow[t]{2}{*}{ Marker } & \multicolumn{2}{|c|}{$\begin{array}{l}\text { All samples } \\
(n=449)\end{array}$} & \multicolumn{2}{|c|}{$\begin{array}{c}\text { Samples } \geq 25 \\
\text { reactions } \\
(n=\mathbf{3 5 8})\end{array}$} \\
\hline & $\begin{array}{l}\text { Reaction } \\
\text { success } a\end{array}$ & $\begin{array}{c}\text { Sample } \\
\text { success } b\end{array}$ & $\begin{array}{l}\text { Reaction } \\
\text { success }\end{array}$ & $\begin{array}{l}\text { Sample } \\
\text { success }\end{array}$ \\
\hline SMMS2 & $91 \%$ & $94 \%$ & $98 \%$ & $100 \%$ \\
\hline SMMS13 & $63 \%$ & $71 \%$ & $74 \%$ & $82 \%$ \\
\hline SMMS16 & $94 \%$ & $95 \%$ & $99 \%$ & $100 \%$ \\
\hline SMMS3 & $86 \%$ & $88 \%$ & $96 \%$ & $98 \%$ \\
\hline SMMS17 & $80 \%$ & $83 \%$ & $91 \%$ & $94 \%$ \\
\hline SMMS18 & $97 \%$ & $98 \%$ & $100 \%$ & $100 \%$ \\
\hline SMMS21 & $92 \%$ & $94 \%$ & $99 \%$ & $100 \%$ \\
\hline 13TAGA & $96 \%$ & $97 \%$ & $99 \%$ & $100 \%$ \\
\hline SM13-410 & $91 \%$ & $94 \%$ & $97 \%$ & $99 \%$ \\
\hline $1 \mathrm{~F} 8 \mathrm{~A}$ & $88 \%$ & $91 \%$ & $96 \%$ & $98 \%$ \\
\hline SMDA23 & $95 \%$ & $97 \%$ & $98 \%$ & $100 \%$ \\
\hline SM13-478 & $94 \%$ & $96 \%$ & $99 \%$ & $100 \%$ \\
\hline $29 \mathrm{E} 6 \mathrm{~A}$ & $94 \%$ & $95 \%$ & $98 \%$ & $99 \%$ \\
\hline $15 \mathrm{~J} 15 \mathrm{~A}$ & $94 \%$ & $96 \%$ & $99 \%$ & $100 \%$ \\
\hline SMU31768 & $99 \%$ & $100 \%$ & $100 \%$ & $100 \%$ \\
\hline
\end{tabular}

${ }^{a}$ Percentage of all reactions which were successful.

${ }^{b}$ Percentage of samples with at least one successful duplicate at that marker. 


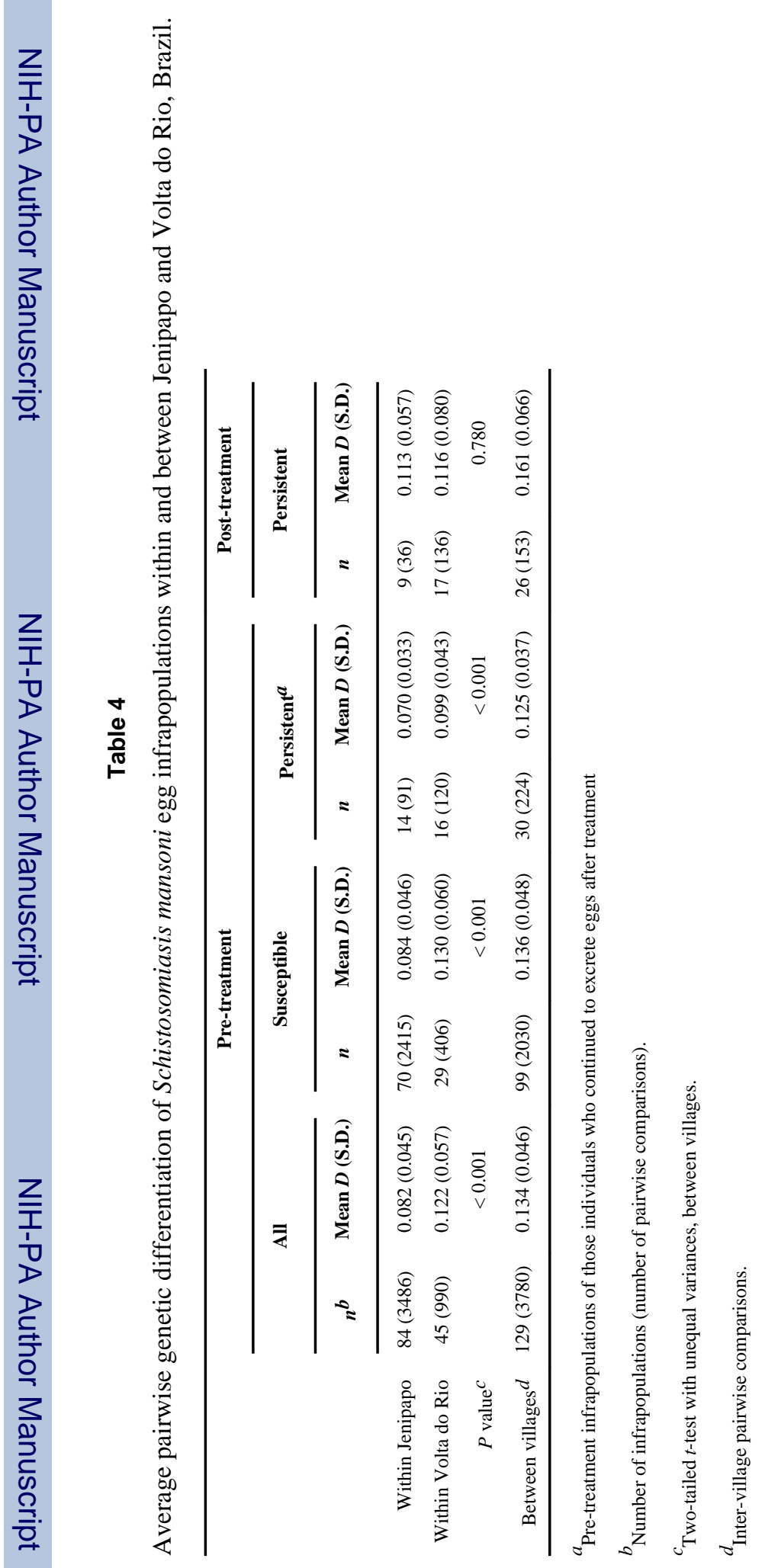




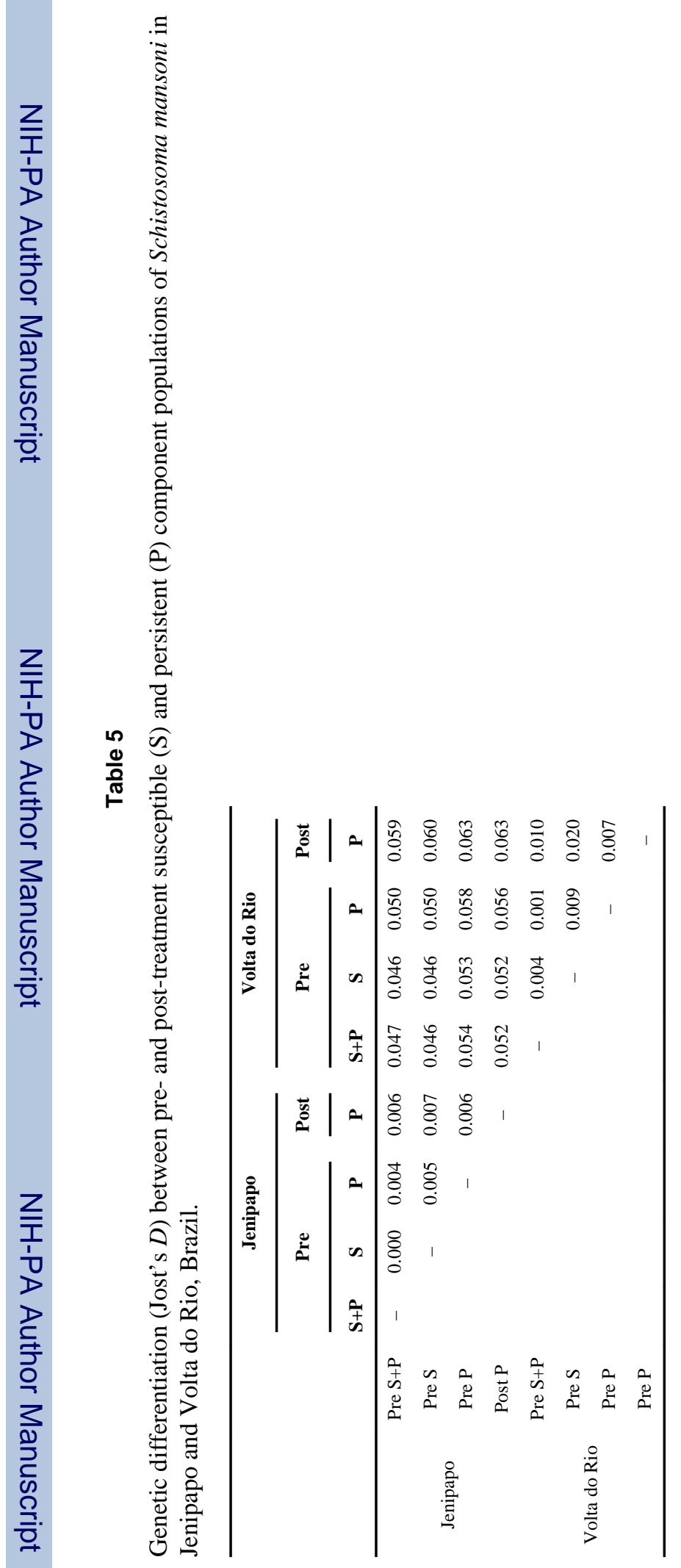

